\title{
Differences in the response to in-phase and out-of-phase multiaxial high-cycle fatigue loading
}

\author{
Jan Papuga, Martin Nesládek, Jiří Kuželka, Josef Jurenka \\ Crech Rep. \\ jan.papuga@fs.cvut.cz,papuga@pragtic.com, bttp:/ / orcid.org/0000-0001-9569-4997 \\ martin.nesladek@fs.cvut.cz,bttp://orcid.org/0000-0003-4606-5849 \\ jiri.kuzelka@fs.cvut.cz, http://orcid.org/0000-0002-2864-9683 \\ josefjurenka@fs.cvut.cz.
}

Dept. of Mechanics, Biomechanics and Mechatronics, Faculty of Mechanical Engineering, Caech Technical University in Prague,

\begin{abstract}
This paper discusses the phase shift effect occurring between two and more load channels of multiaxially loaded specimens. The discussion concludes that there is an extreme shortage of good experimental data that would prove the existence and the trend of the phase shift effect in the highcycle fatigue region. It is no wonder that there are so many fatigue strength estimation criteria that use quite different computational concepts, because the response to the phase shift effect in the experimental base is often hidden in a conglomeration of other interacting effects. The paper presents results of a sensitivity study that compares the fatigue strength estimation results for various such criteria for the same stress amplitudes, but for different phase shifts between the push-pull and torsion load channels. These results show that, with the exception of criteria that assume a zero phase shift effect, the phase shift affects the results of each studied fatigue strength estimation criterion in a different way. A proposal for an experimental setup that would show the real trend unambiguously, and that would enable researchers to check the multiaxial fatigue strength criteria is provided in the paper.
\end{abstract}

KEYWORDS. Proportional loading; Non-proportional loading; Out-of-phase loading; Phase shift; Multiaxial fatigue; Fatigue strength.

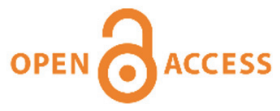

Citation: Papuga, J., Nesládek, M., Kuželka, J., Jurenka, J., Differences in the response to in-phase and out-of-phase multiaxial highcycle fatigue loading, Frattura ed Integrità Strutturale, 50 (2019) 163-183.

Received: 30.11 .2018

Accepted: 24.07 .2019

Published: 01.10.2019

Copyright: (C) 2019 This is an open access article under the terms of the CC-BY 4.0, which permits unrestricted use, distribution, and reproduction in any medium, provided the original author and source are credited.

\section{INTRODUCTION}

$\mathrm{W}$

hat basic conditions must be met before any multiaxial fatigue strength criterion can be classified as good enough? The use of multiaxial criteria is a response to any loading that causes stress/strain tensors to have more than one dominant component. If the loading is proportional, various effective stress/strain values can be chosen to express the overall load effect (see e.g. Tab. 8 in [1]). Non-proportional loading is a more demanding load case. It can be caused by several load channels acting simultaneously, but not in the same phase, not in the same mutual proportion or not with the same load wave shape. The FKM-Guideline [2] defines a separate load class of synchronous loading, where only 
stress amplitudes are proportional. Non-proportional loading can be characterized above all by the fact that the stress (strain) tensor components at any moment are not simple multiples of the tensor at another moment. This condition causes the principal stress directions to rotate during time. For in-phase loading, there are various equivalent values that can be used. However, the question arises: What is the appropriate equivalent stress for non-proportional loading?

Before dealing with this question, it is necessary to specify the research domain focused on in this paper. The area under investigation is the high-cycle fatigue region, where the effect of plasticity is almost negligible in the macroscopic scale. In order to avoid the potential effect of non-homogeneous stress distribution over the critical cross-section, and to skip the potential need to involve its effect in the analysis, only experiments related to unnotched specimens will be studied here. The target of the paper is not just to show the phase shift effect within various experimental data sets, but above all to investigate how well various multiaxial fatigue strength criteria respond to the phase shift effect, and whether they follow the observable and sufficiently proven experimental trends.

One subgroup of non-proportional load cases is the class of out-of-phase loadings. Here, a phase shift can be found between individual load channels that have the same period (and usually correspond to harmonic loading). Many experiments on this topic have been reported in the high-cycle fatigue domain, and they will be discussed later on. One of the most explicit summaries of the findings of previous researchers, in stress-based and also strain-based fatigue life prediction was provided by Sonsino [3], and [4]. His conclusions are that the switch from in-phase loading to out-of-phase loading while keeping the same stress amplitudes on individual load channels causes:

- An increase in the fatigue life in the case of load-controlled loading

- A decrease in the fatigue life in the case of deformation-controlled fatigue tests of unnotched specimens, or in the case of load-controlled loading of notched specimens. This behavior of notched components is attributed to the deformation-controlled loading of the volume around the notch, where the yield stress can be exceeded. Sonsino states that the life reduction is caused by the induced multiaxial hardening. He admits that there are materials that show a decreased fatigue life in this situation, though no multiaxial hardening can be observed, and that some other mechanism may cause this behavior.

To prove this, Sonsino [4] refers to multiple papers and research works. If only the load-controlled fatigue experiments referred to by him in [4] are summarized, it can be found that:

- The data related to the unpublished report by Löwisch and Bomas [5] seem to provide clear proof of the stated behavior.

- Experiments performed by Hug [6] on three different materials, two of which are cited here, also conform to the stated behavior under load control. The behavior is assessed in the region between 1000 and 10000 cycles, in the domain classically referred to as the low-cycle fatigue region. Even the lowest stress levels applied within those tests exceed the yield stress of the virgin material. It is therefore very questionable, whether the reported output confirms Sonsino's conclusions on load-controlled experiments, or whether it undermines his statements concerning the deformation-controlled tests.

- When reporting on Simbürger's experiments in [7], Sonsino refers to the experiments performed in bending and torsion loading of notched specimens, where the observed decrease in the fatigue life confirms his conclusion concerning the behavior of notched components. However, Sonsino did not draw attention to the experiments on hollow specimens loaded by push-pull and torsion, which are described in the same $\mathrm{PhD}$ thesis [7]. These experimental results are reprinted here in Fig. 3, and they show behavior that contradicts Sonsino's summary.

Other comparative analyses of various computational criteria in the HCF domain can be found, see e.g. [1], [7]-[12]. The difference in the response to in-phase loading and to out-of-phase loading is not usually treated separately from other load cases, and in many cases there is only an analysis of the overall prediction errors of all experiments together. The only exception that the authors are aware of is provided by the papers by Papuga [1] and Papuga and Halama [13], where groups of tests conforming to in-phase (IP) and out-of-phase (OP) loading without other partial effects are consistently separated and analyzed.

In order to be able to characterize the typical response to the loading case that is being evaluated, the benchmark test set should contain enough data items reflecting the tested property, so that the typical scatter of fatigue results will not affect the overall output too much. The quality of the benchmark data set of experiments, i.e. a sufficiently proven fatigue characteristic (the whole S-N curve, the fatigue limit, etc.), is a basic requirement for any such analysis. The widely-used benchmark test sets for analyzing the quality of new fatigue strength estimation criteria have some deficiencies. The most widely cited test set, investigated by Nishihara and Kawamoto [14], provides a suitable example. Papuga [15] gives reasons why this test set should be disregarded altogether. The main reason is a general lack of experimental data that enable the fatigue strength (the fatigue limit) to be set with acceptable accuracy - the maximum number of data points used in [14] to define the fatigue limit is 5 , and this number of data points is reached just once in the whole testing campaign on three 
different materials. Another weak point of typical benchmark test sets is that they are often evaluated overall, and not in parts (e.g. in-phase (IP) and out-of-phase (OP) loadings separately). The most widely cited benchmark test set, composed by Papadopoulos et al. [7], therefore comprises 44 data items, which mix together different axial load modes, specimen types, the multiaxiality effect, the mean stress effect, etc. in a single test set. A study of testing hypotheses carried out by Ioannidis [16] concludes that the greater the number of effects that interact in the evaluation, the more dubious the conclusion based on the benchmarking output will be.

Papadopoulos et al. [7] evaluated the Papadopoulos criterion, together with other multiaxial fatigue strength criteria. They found that the intrinsic independence of the Papadopoulos method from the phase shift effect was a more correct approach than other methods, results of which were dependent on the phase shift. For the Papadopoulos criterion, if the stress magnitudes on both load channels are the same for in-phase and out-of-phase load cases, the fatigue life/strength will be the same. The correctness of Papadopoulos' assumption was verified on data sets retrieved from studies by:

- Nishihara and Kawamoto [14], where the experimental results contradict the zero phase shift effect. The non-zero phase shift effect could be traced, if the data could be rated as credible, which they are not [15] as also noted above.

- Lempp [17], where a pronounced non-zero phase shift effect can be traced. The problem when using this data set in any benchmark test is that the fatigue curve in pure torsion, which forms the basic load condition for evaluating any multiaxial fatigue strength criterion, is not credible. Fig. 1 shows the positions of individual data points, which result in a very high standard deviation of the logarithms of cycles $s_{o g N}=0.46$ when a regression analysis is performed to provide the Basquin S-N curve. With such poorly substantiated input data, the test set clearly cannot be used with confidence for quantifying the phase shift effect. It is useful only for comparative purposes between different load cases (see Fig. 1, where multiaxial load cases are also shown).

- Heidenreich [18] and Froustey and Lasserre [19]. Both data sets are well substantiated. They show a close to zero phase shift effect.

A very interesting study on the phase shift effect was published by Pejkowski [20]. He compares the equivalent stress amplitudes under different load modes covering different phase shifts. For high-cycle fatigue, he compares equivalent stress amplitudes at the fatigue limit condition computed from the equivalent stress history defined based on the axial amplitude $\sigma_{a}$ and shear amplitude $\tau_{a}$ as:

$$
\sigma_{e q}=\max _{\omega t} \sqrt{\left[\sigma_{a} \sin (\omega t)\right]^{2}+3\left[\tau_{a} \sin (\omega t-\delta)\right]^{2}}
$$

Parameter $\delta$ corresponds to the phase shift between the two load channels. For an evaluation of fatigue limits, Pejkowski compares data by:

- Nishihara and Kawamoto [14] on hard and mild steels, doubts concerning the validity of which have already been mentioned above. No real quantification of the non-proportionality effect based on these data items can be accepted under these circumstances.

- Rotvel [21], whose experiments concerned pressurizing and axially loading thin-walled tubes. No torsion loading is involved, so the way in which Eq. (1) was used is unclear. The given load combination therefore includes radial, tangential and axial stresses with a different distribution across the wall thickness. This stress state setup does not resemble the axial-torsion setup that is commonly used. The specimens were pressurized from zero to maximum, so the loading must inevitably also involve the mean stress effect.

- Heidenreich et al [18] (ascribed by Pejkowski to Lempp). These data items are the same as those reported by Papadopoulos et al [7]. They show close to zero effect of the phase shift. The comparison with the equivalent stress amplitude in Eq. (1) used by Pejkowski shows a tremendous phase shift effect - its value for the ratio of the shear to normal stress amplitude 0.5 leads to the equivalent stress being approx. $315 \mathrm{MPa}$ for out-of-phase loading and $415 \mathrm{MPa}$ for in-phase loading. The selection of the criteria Eq. (1) for describing the phase shift effect therefore apparently influences the evaluation of the phase shift effect.

- Lempp [17] on 42CrMo4V reported by Papadopoulos et al [7], the experimental data points of which are summed in Fig. 1. Here, too, it seems that the evaluation of the phase-shift effect can only be qualitative and cannot be quantitative.

Pejkowski then continues to other data sets, where he no longer evaluates fatigue limits. He evaluates fatigue lives, which are predicted using the same equivalent stress from Eq. (1) with the common Basquin formulation of the S-N curve.

There is an interesting disproportion in evaluating the phase shift effect as discussed, by Papadopoulos et al. [7] and by Pejkowski [20], on the same data items from Heidenreich et al [18]. Papadopoulos et al. do not believe that the phase shift 
has any impact on the fatigue life, which is manifested in their criterion by comparable stress amplitudes on appropriate load channels for in-phase and out-of-phase loadings. Their assumption is contradicted by a substantial part of the experimental data that they use as a proof. If the data presented by Nishihara and Kawamoto, and by Lempp, show the intrinsic phase shift effect, it projects itself in the values of the error indexes for this criterion. However, a careful check of the results for the whole data set casts doubts on usefulness of these two data sets for quantitatively showing the effect of the phase shift.
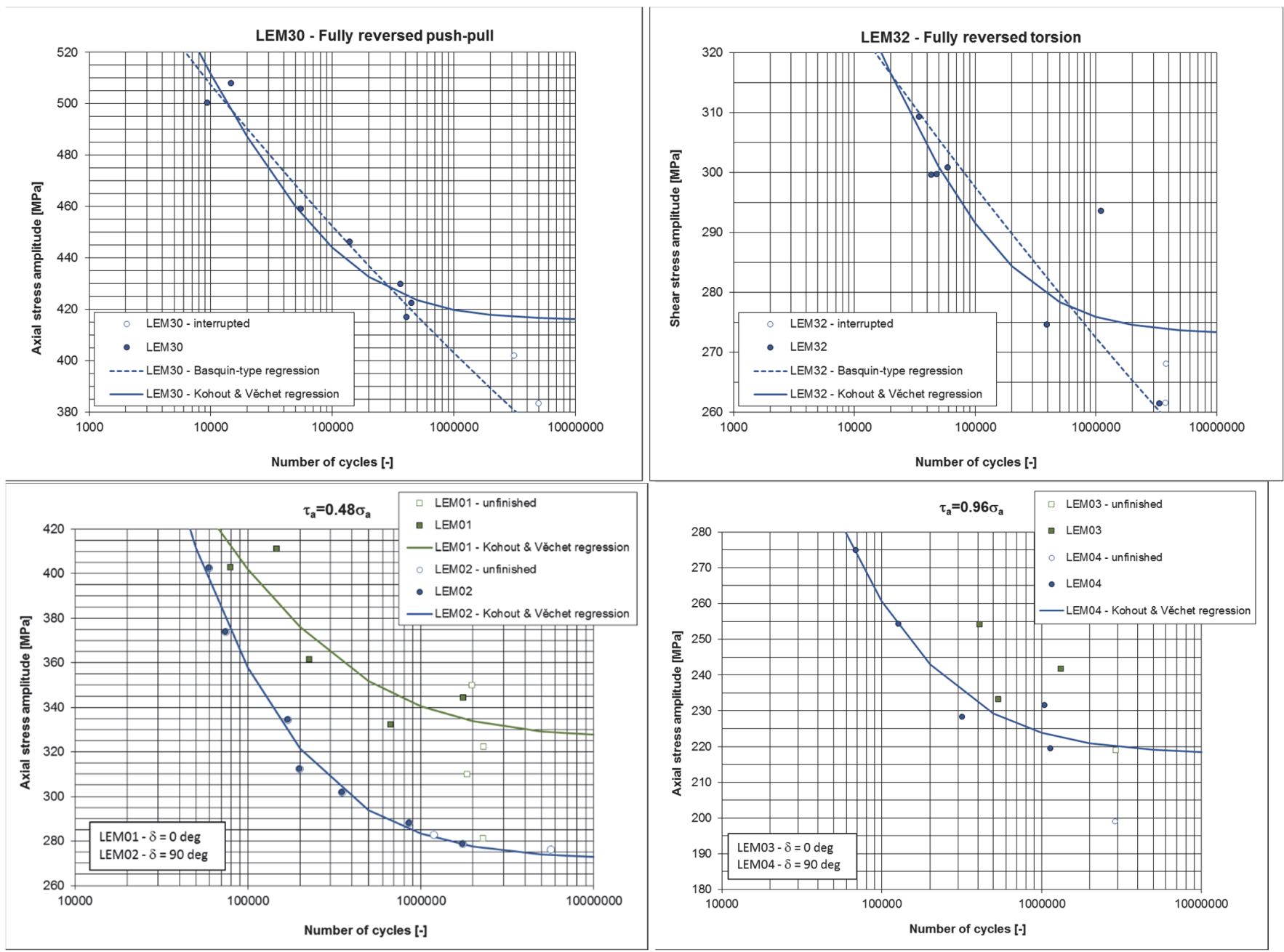

Figure 1: Examples of Lempp's [17] experimental data.

Similar data sets when processed in the equivalent stress amplitude by Pejkowski [20] lead him to the conclusion that outof-phase loading causes a significant reduction in the fatigue limit. This conclusion is driven by the use of the equivalent stress that Pejkowski proposes.

Other equivalent stresses can be proposed to evaluate the phase shift effect. Technically, any multiaxial high-cycle fatigue strength estimation criterion is designed to compute this equivalent stress, which is then compared with the uniaxial fatigue strength for the same lifetime. The correct solution can only be found by evaluating experimental data on various load combinations, including in-phase and out-of-phase data. To avoid any other potential effects that could affect the quantification, only load cases with the same stress ratio (the ratio of the normal stress amplitude to the shear stress amplitude) should be compared. The admissible stress amplitudes for each load case then clearly show whether the fatigue strength rises or falls when a comparison is made between in-phase and out-of-phase load combinations.

This paper addresses the question of the existence of the phase shift effect. The authors have made every effort to build a credible database of multiaxial experiments by collecting data from the available literature and by performing their own experiments. This database was to be used to verify the prediction quality of selected criteria in conditions of multiaxial fatigue with the phase shift effect. To demonstrate only this effect, without mixing it with other effects, the experimental 
procedures and the test specimens must strictly meet a variety of requirements that are introduced and thoroughly discussed in this paper - see the Establishing Data Set section. Detailed consideration of the collected data showed that very few of the experiments can be used to demonstrate that the selected criteria are good for predicting fatigue under non-proportional loading. The subsequent section, Analyzed Calculation Methods, summarizes typical representatives of various types of high-cycle fatigue criteria. The section on Fatigue Strength Prediction Results shows the prediction output of the evaluated criteria. The results are critically evaluated. Although some criteria seem to provide a better response than other criteria, the outcome is not convincing. In the Sensitivity Study section, therefore, there is a summary of the results of numerical experiments that have been conducted with selected criteria, in order to demonstrate the dependency of the predicted fatigue indexes on the phase shift. The Discussion section provides an evaluation of the output. These analyses have led to the idea of compiling a set of conditions and assumptions for an ideal experimental campaign aimed at providing sufficient evidence for an assessment purely of the impact of the phase shift on fatigue damaging.

\section{ESTABLISHING THE DATA SET}

I f only the use of the right equivalent stress hidden in the multiaxial criterion can provide a decisive answer for individual materials and load cases, the data set should be well-established to allow the researcher to quantify the differences between observed and modelled trends. Most of the conditions that the fatigue research team at the CTU in Prague applies for building the data sets for multiaxial fatigue strength analyses are described in [22], and only a brief resume is given here:

- The basic load conditions, for which the fatigue strengths must be defined experimentally, should cover pure fullyreversed axial loading and pure fully-reversed torsion.

- All specimens should be prepared from the same semi-product.

- All specimens used in the experimental data set should have:

○ comparable geometrical characteristics - hollow specimens and bar specimens should not be mixed together;

○ the same thermo-mechanical treatment;

○ the same final roughness;

- no substantial documented anisotropy;

○ no substantial notches to prevent the notch effect interaction;

0 the same criterion for terminating the test.

- Tensile and bending load cases should not be mixed together.

- If possible, raw experimental data are the optimum source, but information about the loading can be retrieved from graphs, if necessary.

- Depending on the type of testing campaign, the fatigue strengths are obtained either from the staircase method or from the section cut at a given number of cycles through the S-N curve obtained from a regression analysis of the experimental points. An adequate count of data points is needed for both approaches.

For the study presented here, further rules must be applied to filter out any other undesired effect. These rules will be discussed below.

\section{The basic test set}

In order to focus only the phase shift effect, further restrictions are appropriate:

- Experiments with non-zero mean stresses must be removed.

- Only combined axial and torsion loadings are admitted. Inner pressurizing of tube specimens intrinsically causes non-zero mean stresses. There are several cases where outer pressure is also applied [25], [26], but the pressure is not alternating. There is at least one case of another potentially interesting load combination using cruciform specimens [27], but the numbers of specimens used for each fatigue curve are not big enough.

- Cases, where the same stress ratio between the stresses caused by two load channels is applied to the in-phase combination and also to the out-of-phase combination will be used as the optimum input, but other setups are also possible (e.g. the FF test data [25]).

A minimum of four experimentally obtained fatigue strengths is therefore needed to define one studied unit: (1) alternate push-pull; (2) alternate torsion; (3) an in-phase alternating push-pull and alternating torsion combination with a given stress ratio; (4) an out-of-phase combination of alternating push-pull and alternating torsion loading with the same stress ratio. 
The stress gradient at plane bending

Much experimental data in multiaxial fatigue has been generated with the axial stress resulting from plane bending. Machines capable of such a load combination induced mechanically were frequently used in early research on multiaxial fatigue, above all because of their simplicity [28] - [31]. The same good reason explains why they are still used now [11], [32]. Plane bending includes the stress gradient effect, which is not present in push-pull. More specifically, when compared to the state of homogeneous stress across the cross-section, the stress gradient results in lower stress intensity factor values and the crack growth is slower in this case. Only the outer layers of the material are more loaded up to the limit condition, and the crack is initiated there. Because the stress level deeper in the cross-section is smaller, the crack growth rate is substantially different from the push-pull condition.

The stress gradient effect is also intrinsic to torsion loading. As was noted above, there is only limited experience of highcycle fatigue loading using cruciform specimens loaded biaxially, which can generate pure shear stress states almost unaffected by the stress gradient. Torsion loading must therefore be accepted as an unpleasant but unavoidable variant. In the case of axial loads, there is still a chance to reduce the complexity of the simulated damaging effects by admitting only load cases where the axial load is induced by push-pull. A logical requirement could be to ensure concentricity of the system comprising machine grips and the specimen, in order to induce a constant stress distribution across the cross-section unaffected by any additional parasitic bending. Unfortunately, most data sources do not refer to any check of this kind being performed during the testing campaign.

\section{Fatigue damaging stages}

Another unspoken reason for avoiding stress gradients in the experiments is that an analysis of the real conditions in the specimens could show that the ratio between the crack initiation phase and the crack growth phase might differ for different load conditions. The idealized image is that the crack initiation phase is prevalent in high-cycle fatigue, and a partial confirmation could be found e.g. in [33]. Let us consider the experiments by Klubberg et al. [34]. Their study on GJL-250 cast iron shows two conditions. For bar specimens $12 \mathrm{~mm}$ in diameter, the fatigue limits are $130.0 \mathrm{MPa}$ in fully reversed torsion and $114.1 \mathrm{MPa}$ in push-pull. If hollow specimens $33 \mathrm{~mm}$ in outer diameter and $28 \mathrm{~mm}$ in inner diameter are used, the fatigue limits decrease to $77.5 \mathrm{MPa}$ in fully reversed torsion and to $76.5 \mathrm{MPa}$ in push-pull.

The fatigue strength ratio between the fatigue limit in push-pull and the fatigue limit in torsion for bar specimens is 0.84 . This value is quite unusual, and it is in contradiction with any equivalent stress theory (see also the reasoning in [13]). If hollow specimens are used, the fatigue strength ratio ends up as 0.99. Given the intrinsic scatter for cast iron, this can be interpreted as a value close to 1.0 , which conforms very well with the static strength hypothesis of the maximum principal stress, which is relevant for brittle materials. This geometrical configuration therefore correlates better with the expected physical configuration.

The perimeter of the bar specimens is about 2.5 times shorter than the perimeter of the hollow specimens, which can partly explain the higher fatigue strength values achieved in torsion caused by the size effect. The length of the perimeter is related to the probability of finding the critical inclusion to initiate the crack - the longer it is, the greater is the probability, so the fatigue strength should be reduced. Similarly, the cross-section of the bar specimens is about twice smaller than the crosssection of the hollow specimens. This can partly explain the lower fatigue strength in axial loading of the hollow specimen. The observed change in the fatigue strength ratio can be ascribed to the differences in proportion between the phase of fatigue crack initiation and the phase of fatigue crack growth. The crack surface can show traces of so-called factory-roof topology (see e.g. [35]). This kind of crack morphology can slow down the fatigue crack growth phase, and this may be the reason for the unexpected results for the bar specimens, as was noted above. Another reason can be discussed on the basis of Fig. 2, which sketches the SAE 1045 response to axial and torsion loadings reported in full by Socie [33]. The two load cases differ in the mutual proportion of the crack initiation phase and the crack growth phase within the total life. A similar kind of difference is therefore likely to be found in any combination of these cases. If the crack growth phase observed in high-cycle fatigue could be found to be negligible for the case of a tensile load, the converse is true for the case of torsion. It is surely unlikely that the crack growth phase could be driven by the same failure mechanisms as the crack initiation phase. It is therefore not reasonable to assess the crack growth phase within the total lifetime evaluated by the crack initiation criterion.

In the case of hollow thin-walled specimens, any initiated crack grows quickly. The specimen is broken soon after crack initiation. Even the shear stresses on the outer and inner surface of the tube are closer, and the support effect of the core of the bar is missing here. In summary, only experiments performed on hollow specimens should be admitted to the data set describing solely the phase shift effect. 

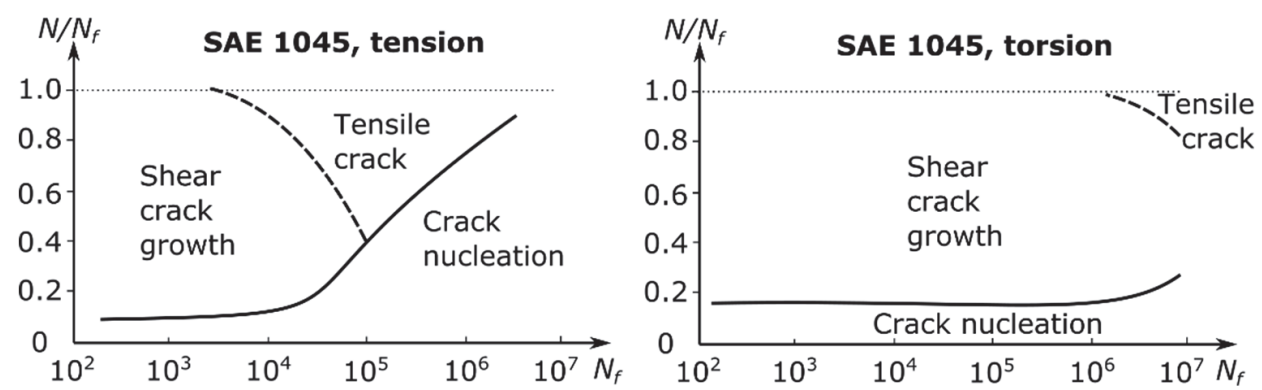

Figure 2: This sketch based on Socie's findings reported in [33] shows the differences in crack initiation and growth phases for tension and torsion load modes.

\section{The final test data}

Paper [36] reports on a complete set of 15 IP/OP pairs before additional requirements were applied (removal of bar specimens, and removal of bending loading). If the target set is isolated according to the criteria described above, only 5 pairs will remain, see Tab. 1, for which a summary of the test setup and the material properties are given in Tab. 2. The quality of the experimental data can also be judged from Figs. 3-5, which show how many data points were used to derive the S-N curves, and how they are scattered. The Basquin two-parametric formula was used only for the two-load level S-N curve setup of Simbürger's experiments [7], because alternative Kohout-Věchet function [37] does not provide a good regression for fatigue tests just on 2 load levels.

\begin{tabular}{|c|c|c|c|c|c|c|c|}
\hline Material & $N$ & Test case ID & $\sigma_{a, N}[\mathrm{MPa}]$ & $\tau_{a, N}[\mathrm{MPa}]$ & $\sigma_{a, N} / \tau_{a, N}$ & $\delta[\mathrm{deg}]$ & $\sigma_{M M P, O P} / \sigma_{M M P, I P}$ \\
\hline \multirow[t]{2}{*}{ Ck45 [7] } & \multirow[t]{2}{*}{100000} & SiB011 & 326.8 & 187.9 & 1.74 & 0 & \multirow{2}{*}{0.94} \\
\hline & & SiB013 & 308.2 & 177.2 & 1.74 & 90 & \\
\hline \multirow[t]{4}{*}{ ČSN 411523 [25] } & \multirow[t]{4}{*}{500000} & FF001 & 99.4 & 153.4 & 0.65 & 0 & \multirow{2}{*}{1.04} \\
\hline & & FF003 & 99.4 & 158.9 & 0.63 & 90 & \\
\hline & & FF002 & 194.4 & 108.2 & 1.80 & 0 & \multirow{2}{*}{1.15} \\
\hline & & FF004 & 194.0 & 143.6 & 1.35 & 90 & \\
\hline \multirow[t]{4}{*}{ 2124-T851 [38] } & \multirow[t]{4}{*}{200000} & FAD007 & 98.7 & 98.3 & 1.00 & 0 & \multirow{2}{*}{0.96} \\
\hline & & FAD009 & 89.7 & 89.6 & 1.00 & 90 & \\
\hline & & FAD008 & 154.8 & 51.6 & 3.00 & 0 & \multirow{2}{*}{0.97} \\
\hline & & FAD010 & 143.6 & 48.0 & 2.99 & 90 & \\
\hline
\end{tabular}

Table 1: Data from in-phase and out-of-phase experiments gathered in the final test set.

\begin{tabular}{llrlrrrrrr}
\hline Set ID & Material & $S_{u}[\mathrm{MPa}]$ & $N[-]$ & $p_{-1, N}[\mathrm{MPa}]$ & $t_{-1, N}[\mathrm{MPa}]$ & $\kappa_{N}[-]$ & $D[\mathrm{~mm}]$ & $d[\mathrm{~mm}]$ & $d / D[-]$ \\
SiB & Ck45 & 850.0 & 100000 & 419.6 & 286.2 & 1.47 & 35 & 32 & 0.91 \\
FF & ČSN 41 1523 & 560.0 & 500000 & 250.8 & 170.6 & 1.47 & 11 & 8 & 0.73 \\
FAD & 2124-T851 & 477.1 & 200000 & 177.2 & 120.1 & 1.48 & 18 & 16 & 0.89 \\
\hline
\end{tabular}

Table 2: Material parameters related to the experiments in Tab. 1. Nomenclature: $S_{u}$ - tensile strength, $p_{-1, N}-$ fatigue strength at $N$ cycles in fully-reversed push-pull loading, $t_{-1, N}$ - fatigue strength at $N$ cycles in fully-reversed torsion, $\kappa_{N}=p_{-1, N} / t_{-1, N}-$ fatigue strength ratio at $N$ cycles, $D$ - major diameter of the specimen in the critical section, $d$-minor diameter of the specimen in the critical cross-section. 


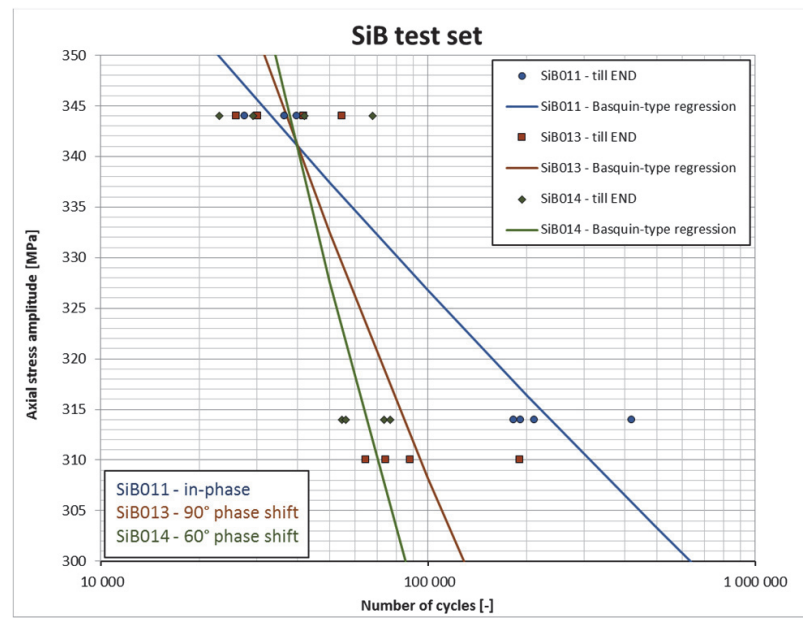

Figure 3: Simbürger's [7] experimental data following the two-level testing strategy, and the final regression lines.
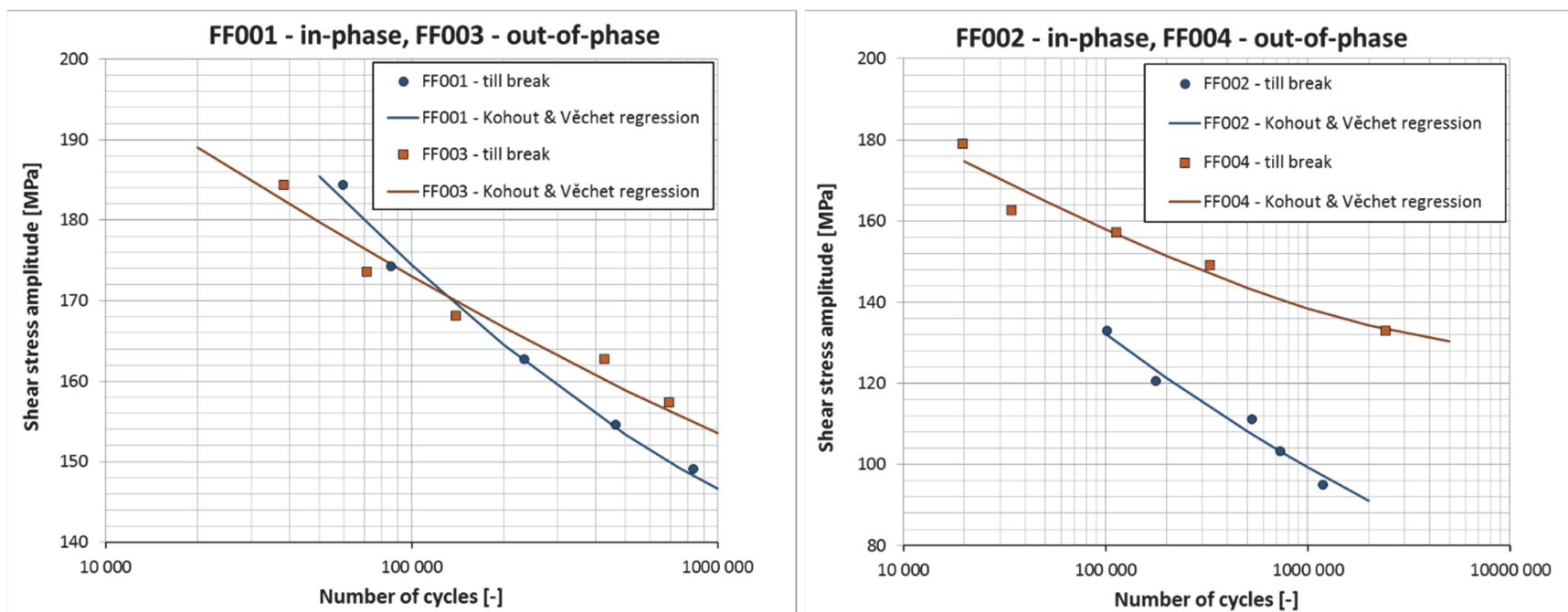

Figure 4: FF [25] experimental data representing the pearl string testing strategy, and the final regression lines. Note that the shear stress amplitude is depicted as the stress parameter.
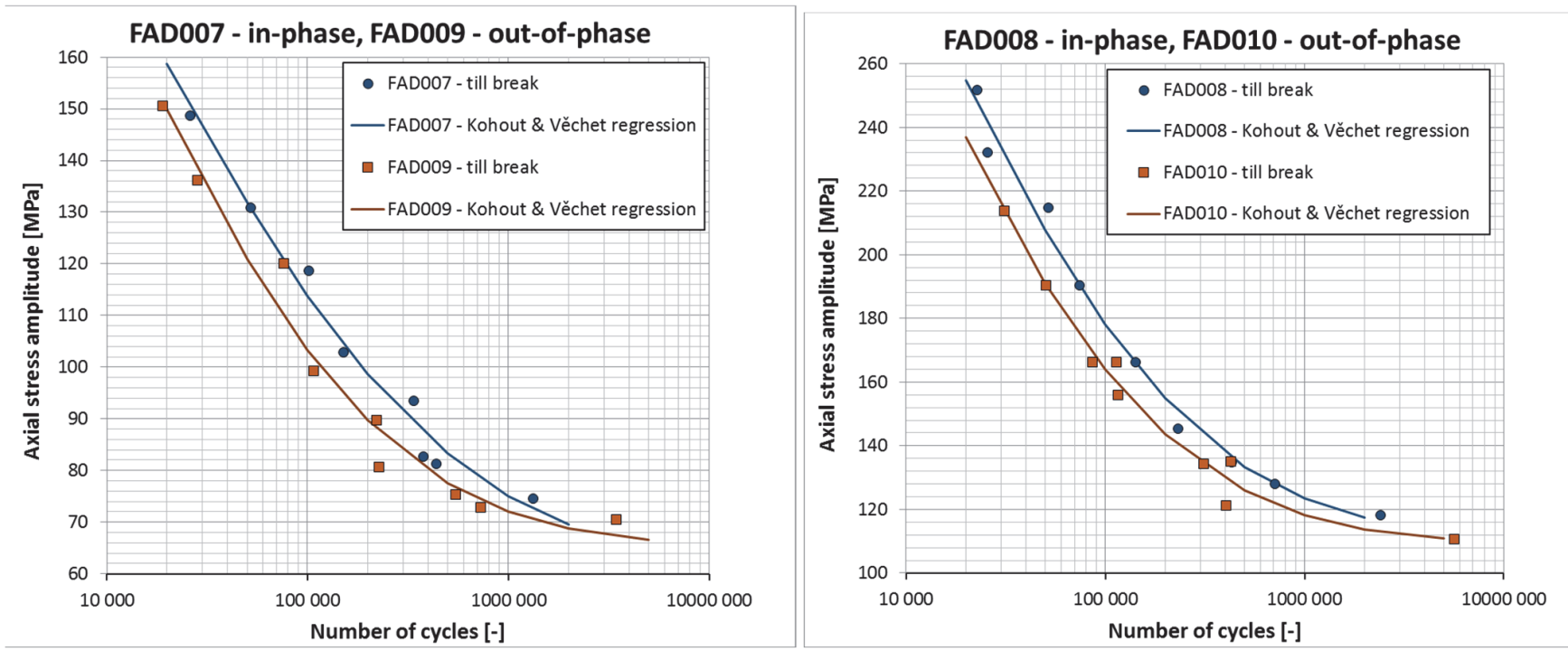

Figure 5: Another representative of pearl string strategy testing in FAD [38] experimental data. 
Experiments in the FF data set do not keep to the traditional approach, in which the stress ratio is kept constant at different stress amplitude levels. A constant stress is maintained in the tensile load channel, and there is a variable shear torsion. The stress ratio is therefore not the same for in-phase loading and for out-of-phase loading. In order to be able to analyze the phase shift effect quickly, the equivalent stress based on the MMP criterion [25] is used. For the case without any mean stresses, it can be simplified to:

$$
\sigma_{M M P}=\sqrt{\sigma_{a}^{2}+\kappa^{2} \cdot \tau_{a}^{2}}
$$

\section{ANALYZED CALCULATION METHODS}

There is a wide range of multiaxial fatigue strength estimation methods. An extensive survey of their prediction capability was published by Papuga [1]. There are not only differences in the formulas, but the approach to the analysis can also vary. Representatives of different approaches have therefore been selected here for testing. In [1], Papuga highlighted that many multiaxial methods suffer from poor implementation of the mean stress effect. The methods selected here will therefore be derived mainly on basis of their performance from Tab. 8 in [1], which presents data without the mean stress effect. The differences between the methods, and their basic formulas, are described below. The reader can find a more detailed description e.g. in [1].

\section{Critical plane with maximum damage}

This group of methods analyses the damage parameter on every possible orientation of a plane. The plane on which the maximum damage parameter value is found is claimed to be the critical plane.

The method with the best performance in [1] is the Papuga PCR method. Its newer update, published in [13], differs only in the implementation of the mean stress effect. The methods are identical if no mean stress is involved, and the methods can be reduced to the formula:

$$
\sqrt{a_{P C} \cdot C_{a}^{2}+b_{P C} \cdot N_{a}} \leq p_{-1}
$$

where $C_{a}$ corresponds to shear stress amplitude, and $N_{a}$ corresponds to the normal stress amplitude, on the evaluated plane. The second method with the best performance is the QCP method. It can be reduced to:

$$
\sqrt{a_{Q C P} \cdot C_{a}^{2}+b_{Q C P} \cdot N_{a}^{2}} \leq p_{-1}
$$

\section{Critical plane with the maximum shear stress range}

This type of solution determines the critical plane on basis of the maximum shear stress range (MSSR) found on it. The concept thus denies any additional impact of other stress components (typically the normal stress) on the orientation of the critical plane. The most prominent method here is the Susmel method [39] (the title is shortened to SUS in Tab. 3):

$$
a_{S u} \cdot C_{a}+b_{S u} \cdot \frac{N_{a}}{C_{a}} \leq p_{-1}
$$

and the Matake method [40] (which is similar to the McDiarmid method [41], but coefficients $a$ and $b$ would differ), denoted as MAT in Tab. 3:

$$
a_{\text {Mat }} \cdot C_{a}+b_{\text {Mat }} \cdot N_{a} \leq p_{-1}
$$

\section{Dang Van method}

The Dang Van solution is the leading multiaxial fatigue strength calculation method in commercial applications today. The method is in fact a mix of the two critical plane technologies noted above. The reason is that the second parameter, in 
addition to the shear stress amplitude, is an invariant value - it is the hydrostatic stress. The original criterion [42] (marked as DVO in Tab. 3) mixes the current hydrostatic stress and the shear stress excursion value together at the same moment:

$$
\max \left(a_{D V} \cdot C_{a}(t)+b_{D V} \cdot \sigma_{H}(t)\right) \leq p_{-1}
$$

See also the description in [13]. In [1], Papuga used another variant (marked as DVM in Tab. 3), which, he claims [13], suppresses the extreme non-conservativeness of the original Dang Van solution:

$$
a_{D V} \cdot C_{a}+b_{D V} \cdot \sigma_{H, a} \leq p_{-1}
$$

The results in [13] show that the method remains excessively non-conservative for out-of-phase loading.

\section{Integral criteria}

Integral solutions differ from the critical plane solution in that the damage parameters retrieved from the stresses on individual planes are not maximized - they are integrated over all possible orientations. Logically, this is a completely different concept for an analysis of the local stress states. It is surprising that the results of the newly introduced Papuga PCR (critical plane) and PI (integral) parameters in [43], [1] do not differ substantially. Integral methods are not at present implemented in any commercial fatigue solver. The reason for this could be the computational cost - the integration scheme could be more demanding on analyzing the space than the widely-used maximization procedure that is relevant for critical plane schemes. Tomčala et al prove in their sensitivity study [44] that if the same computational error induced by discrete evaluation plane-by-plane is admitted for the critical plane and for integral concepts, the number of planes to be evaluated is approximately two times lower for the integral solution.

Kenmeugne et al [45] proposed that the optimum application of the integral concept can be assumed to be for cases of frequent principal directions rotations, which are intrinsic e.g. for random loading on two load channels. Note that this assumption cannot be explicitly confirmed due to enormous requirements on the benchmark set. However, integral solutions do not seem to have lower prediction capability than the critical plane solutions in [1], although only constant amplitude loadings are involved there. Among the evaluated integral criteria in [1], the best results are provided by the Papuga PI method

$$
\sqrt{\left[\int a_{P I} \cdot C_{a}^{2}+b_{P I} \cdot N_{a}\right] \sin \psi d \psi d \varphi} \leq p_{-1}
$$

followed by the Liu \& Zenner solution [23], (shortened to L\&Z in Tab. 3) solution:

$$
\sqrt{\left[\int a_{P I} \cdot C_{a}^{2}+b_{P I} \cdot N_{a}^{2}\right] \sin \psi d \psi d \varphi} \leq p_{-1}
$$

\section{Part-by-part integration}

The Papadopoulos method [7] discussed in this section, and marked as PAPA in Tab. 3, can be classified as an integral solution. It is categorized in a separate subsection, because of the way in which the integration is performed. This method integrates the resolved shear stress over all directions over all possible planes. The integration of the normal stress over all possible planes can be mathematically proven to be equal to the hydrostatic stress. The method can therefore be written:

$$
\sqrt{a_{P a p} \cdot \iiint T_{a}^{2} d \chi \sin \psi d \psi d \varphi}+b_{P a p} \cdot \sigma_{H, a} \leq p_{-1}
$$

In the case presented here, where only the axial $\sigma_{a}$ and shear stress $\tau_{a}$ amplitudes are active in harmonic loading and with whichever phase shift, the criterion reduces to a simple formula:

$$
\kappa \cdot \sqrt{\frac{\sigma_{a}^{2}}{3}+\tau_{a}^{2}}+\left(1-\frac{\kappa}{\sqrt{3}}\right) \cdot \sigma_{a} \leq p_{-1}
$$


All previously stated criteria involve shear stress amplitudes and normal stress amplitudes on various assessed planes, which depend on the acting stress amplitudes, and also on the phase shift between the two signals. In spite of the seeming complexity of Eq. (11) the criterion reduces to a formula Eq. (12) that does not involve the phase shift. This obviously manifests a zero phase shift effect. Note that Papadopoulos [7] limits the validity of his method to ductile materials $1.2<\kappa$ $<1.73$.

\section{Invariant-based criteria}

The stress parameters involved in an analysis of this type are based on invariant stress parameters. Typically, the parameters are the amplitude of the second stress deviator, usually denoted as $V_{2, a}$, and some accompanying invariant value such as the hydrostatic stress. The comparison in [1] clearly shows that the Crossland method (CRO in Tab. 3):

$$
a_{C} \cdot \sqrt{J_{2, a}}+b_{C} \cdot \sigma_{H, a} \leq p_{-1}
$$

leads to substantially better results than the Sines method (see both in [1], or in [7]).

\section{Critical plane deviation}

The method by Liu \& Mahadevan [24] (its title is shortened to L\&M in Tab. 3) has been selected as a representative of the small group of criteria, that look first for the critical plane based on the damage parameter, and then run a second step in the search for the fracture plane inclined from it by some angle based on the properties of the material. The damage parameter is expressed as:

$$
\sqrt{a_{L M} \cdot C_{a}^{2}+b_{L M} \cdot N_{a}^{2}+e_{L M} \cdot \sigma_{H, a}^{2}} \leq p_{-1}
$$

\section{The MMP method}

This method was recently proposed by Papuga and Fojtík [25]. Due to its definition of the damage parameter:

$$
\sqrt{\sigma_{a}^{2}+\kappa^{2} \cdot \tau_{a}^{2}} \leq p_{-1}
$$

it is obvious that the method denies that there is any phase shift effect.

\section{FATIGUE STRENGTH PREDICTION RESULTS}

he results for the quality of the fatigue strength estimates provided by the listed methods can be found in Tab. 3 . The fatigue index FI is defined to describe the measure, in which the damage parameter (left-hand side LHS) of the Eqs. (3)-(15) approaches the fatigue strength in fully reversed push-pull $p_{-1}$ (i.e. the right-hand side RHS of Eqs. (3)-

(15):

$$
F I=\frac{L H S}{R H S}
$$

If the admissible stress is evaluated, FI should be equal to 1.0. The fatigue index error used for evaluating the prediction errors therefore equals:

$$
\Delta F I=F I-1
$$

The test data set items are so sparse, that it makes little sense to perform a statistical evaluation of them, as shown e.g. in [1]. The highlighting of the background of cells in Tab. 3 indicates cases where the methods are not able to cope well enough with the experimental data. It soon becomes apparent that the two Dang Van methods result in bad predictions of out-of- 
phase cases. Their results tend to be excessively non-conservative, with the exception of the FF cases, where only case FF003 is acceptably well described, while FF004 is distinctly over-conservative.

Similar over-conservativeness of all criteria to the FF004 case can be observed, which casts doubts on the data inputs. Are all classes of criteria really wrong in determining the right response? A more detailed insight into the FF set [25] shows that only a limited number of experimental setups were run while using hollow specimens with outer diameter $D=11 \mathrm{~mm}$ and inner diameter $d=8 \mathrm{~mm}$ outer and inner diameters. This setup includes all experiments FF001-FF004, and also the fully reversed and repeated tension load conditions.

The pure alternate torsion experiment in the FF test series was run on hollow specimens with diameter $D=20 \mathrm{~mm}$ and $d=18$ $\mathrm{mm}$. The cross-section area of the larger specimens is $33 \%$ greater than that of the smaller specimen types. The length of the perimeter is more important, and here the ratio between two types of specimens shows that the bigger specimens have an $82 \%$ longer perimeter. Thus the size of the domain, in which a fatigue crack can initiate, is substantially bigger. It can therefore be concluded that the torsion fatigue strength $t_{-1, N}$ used in the analyses here is likely to be underestimated for smaller specimens.

\begin{tabular}{llllllllllllll}
\hline Test case & $\delta[\mathrm{deg}]$ & PCR & QCP & SUS & MAT & DVO & DVM & PI & L\&Z & PAPA & CRO & MMP & L\&M \\
\hline SiB011 & 0 & 5.16 & 1.85 & 4.53 & 7.87 & 7.78 & 7.78 & 0.09 & 1.81 & 4.96 & 4.99 & 1.85 & 4.84 \\
SiB013 & 90 & -1.66 & -4.07 & 8.37 & 1.16 & -26.54 & -18.46 & -1.42 & -8.17 & -1.08 & -26.49 & -3.92 & -12.90 \\
\hline FF001 & 0 & 3.35 & -1.77 & 2.67 & 5.13 & 4.99 & 4.97 & -1.42 & -1.81 & 1.93 & 1.97 & -1.78 & 1.61 \\
FF003 & 90 & 5.93 & 1.20 & 5.50 & 8.23 & 8.08 & 8.04 & 0.60 & 1.17 & 4.98 & 5.01 & 1.19 & 4.65 \\
\hline FF002 & 0 & 3.75 & 0.18 & 3.01 & 5.97 & 5.84 & 5.84 & -0.98 & 0.15 & 3.12 & 3.15 & 0.15 & 3.01 \\
FF004 & 90 & 16.31 & 14.33 & 16.43 & 22.26 & 22.09 & 22.09 & 8.28 & 14.29 & 18.43 & 18.47 & 14.30 & 18.21 \\
\hline FAD007 & 0 & 4.14 & -1.00 & 3.37 & 6.35 & 6.20 & 6.20 & -1.32 & -1.03 & 2.83 & 2.86 & -0.99 & 2.56 \\
FAD009 & 90 & -3.57 & -9.93 & 0.89 & 1.20 & -23.98 & -12.09 & -5.37 & -13.62 & -6.41 & -17.87 & -9.81 & -6.66 \\
\hline FAD008 & 0 & -0.10 & -2.65 & -0.72 & 0.49 & 0.36 & 0.36 & -2.54 & -2.69 & -1.17 & -1.14 & -2.65 & -1.16 \\
FAD010 & 90 & -8.78 & -9.96 & -8.71 & -14.69 & -18.98 & -18.98 & -5.32 & -12.03 & -8.37 & -18.98 & -9.67 & -13.74 \\
\hline
\end{tabular}

Table 3: Results of the fatigue index error $\Delta F I[\%]$ obtained for individual items in the test set.

It can therefore be expected that the results using too small fatigue strength in torsion will tend to be too conservative, and this is confirmed by all FF data in Tab. 3 - none of the results shows the fatigue strength estimate to be non-conservative. This complete analysis leads to a straightforward conclusion. The fatigue strength in pure torsion loading $t_{-1, N}$ was obtained from bigger specimens. Its use for specimens for load cases FF001-FF005, carried out on smaller specimens with a thicker wall, cannot be recommended. The cross-sectional areas do not differ greatly, so the use of the fully-reversed push-pull fatigue strength $p_{-1, N}$ for other load cases tested on larger specimens is insufficiently sensitive. However, the criteria applied for forming the test batch for an analysis of the phase-shift effect does not allow the FF test data to be applied.

Though the $\mathrm{SiB}$ test set is included in the final test set, some doubts should be expressed. The $\mathrm{SiB}$ test set was prepared on basis of experimental data reported by Simbürger [7], who performed all the S-N experiments only on two load levels. In fact, the presumption that the $\mathrm{S}-\mathrm{N}$ functions in between those two levels form a straight line in a bi-logarithmic graph (i.e. that there is a power law, as modelled e.g. by the Basquin function), is a mere fantasy unsupported by other experimental evidence. The probable trend is obvious (the application of a non-zero phase shift worsens the fatigue strength/life), but the quantification of this effect is far from being exact

The team led by Papuga prepared a benchmark testing set [22] based on a literature analysis of more than 250 different papers, reports and theses. Most experimental data fail conform with some of the requirements for statistical reliability, and misleading data can be found even in the final selection. This shows that much more care needs to be given to the preparation and the running of the experiments. Unless the requirements emphasized above are complied with, it is not possible to determine the role that the phase shift plays in high-cycle fatigue. 


\title{
SENSITIVITY STUDY
}

\begin{abstract}
A further study of the paper by Ioannidis [16] shows that it is not sufficient to select the test benchmark appropriately in order to remove other potential effects. Another important consideration, if really reliable analysis output is to be achieved, is whether the effect being analyzed is strong enough. Tab. 3 shows that if the FF experiments and the worst DVx criteria are omitted, the typical scatter of the fatigue strength estimate is between approx. $-15 \%$ and $+10 \%$. A numerical analysis, which will be described below was run to answer the question: Is the phase-shift effect strong enough to be analyzed? Three material characteristics were set that are typical for brittle, ductile and extra-ductile materials (similar to the classification proposed by Papadopoulos et al [7]), see Tab. 4. Four different stress ratios between axial stress and shear stress were selected for each of the three characteristics. These load cases were not tested. They are just a proposal for stress amplitudes, which for in-phase loading result in the fatigue index retrieved from the PCR method (and they are therefore abbreviated to $\left.F I_{P C R, 0}\right)$ close to 1.0. The stress amplitudes were the same for all analyzed phase shifts, while the phase shifts varied from $0^{\circ}$ to $180^{\circ}$ with a step of $5^{\circ}$. The final fatigue indexes obtained for each material and load combinations were then normalized by the fatigue index obtained for the in-phase combination of the same stress ratio.
\end{abstract}

\begin{tabular}{|c|c|c|c|}
\hline & $\begin{array}{c}\text { Brittle, } \kappa=1.07 \\
t_{-1}=280 \mathrm{MPa}\end{array}$ & $\begin{array}{c}\text { Ductile, } \kappa=1.58 \\
t_{-1}=190 \mathrm{MPa}\end{array}$ & $\begin{array}{c}\text { Extra-ductile, } \kappa=1.82 \\
t_{-1}=165 \mathrm{MPa}\end{array}$ \\
\hline$\sigma_{a} / \tau_{a}=2.63$ & $\begin{array}{c}\sigma_{a}=250 \mathrm{MPa} \\
\tau_{a}=95 \mathrm{MPa} \\
F I_{P C R, 0}=0.969\end{array}$ & $\begin{array}{c}\sigma_{a}=250 \mathrm{MPa} \\
\tau_{a}=95 \mathrm{MPa} \\
F I_{P C R, 0}=0.998\end{array}$ & $\begin{array}{c}\sigma_{a}=250 \mathrm{MPa} \\
\tau_{a}=95 \mathrm{MPa} \\
F I_{P C R, 0}=1.024\end{array}$ \\
\hline$\sigma_{a} / \tau_{a}=1.73$ & $\begin{array}{c}\sigma_{a}=213 \mathrm{MPa} \\
\tau_{a}=123 \mathrm{MPa} \\
F I_{P C R, 0}=0.947\end{array}$ & $\begin{array}{c}\sigma_{a}=213 \mathrm{MPa} \\
\tau_{a}=123 \mathrm{MPa} \\
F I_{P C R, 0}=1.000\end{array}$ & $\begin{array}{c}\sigma_{a}=213 \mathrm{MPa} \\
\tau_{a}=123 \mathrm{MPa} \\
F I_{P C R, 0}=1.046\end{array}$ \\
\hline$\sigma_{a} / \tau_{a}=1.00$ & $\begin{array}{c}\sigma_{a}=150 \mathrm{MPa} \\
\tau_{a}=150 \mathrm{MPa} \\
F I_{P C R, 0}=0.899\end{array}$ & $\begin{array}{c}\sigma_{a}=150 \mathrm{MPa} \\
\tau_{a}=150 \mathrm{MPa} \\
F I_{P C R, 0}=0.984\end{array}$ & $\begin{array}{c}\sigma_{a}=150 \mathrm{MPa} \\
\tau_{a}=150 \mathrm{MPa} \\
F I_{P C R, 0}=1.058\end{array}$ \\
\hline$\sigma_{a} / \tau_{a}=0.29$ & $\begin{array}{c}\sigma_{a}=50 \mathrm{MPa} \\
\tau_{a}=170 \mathrm{MPa} \\
F I_{P C R, 0}=0.810\end{array}$ & $\begin{array}{c}\sigma_{a}=50 \mathrm{MPa} \\
\tau_{a}=170 \mathrm{MPa} \\
F I_{P C R, 0}=0.942\end{array}$ & $\begin{array}{c}\sigma_{a}=50 \mathrm{MPa} \\
\tau_{a}=170 \mathrm{MPa} \\
F I_{P C R, 0}=1.055\end{array}$ \\
\hline
\end{tabular}

Table 4: The setup for the sensitivity analysis for the phase shift effect. The same fatigue strength in fully-reversed push-pull $p_{-1}=300$ $\mathrm{MPa}$ was used in all cases. The table also refers to fatigue indexes $F I_{P C R, 0}$ obtained under given conditions (axial stress amplitude $\sigma_{a}$, shear stress amplitude $\tau_{a}$ ) by the PCR method for in-phase loads.

All computations of the sensitivity analysis described below were run in PragTic fatigue solver [46]. It is openly available, and anybody can test its computational quality. The Job File task file [47] serves as a reference confirming its validity [46]. If normalization by $F I_{x x x ; 0}$ is applied to every $x x x$ criterion, graphs of the phase-shift effect dependency can be drawn, as shown in Figs. 6-10. It is clear that the phase shift behavior of each method is specific - the response to these numerical tests can be understood as a kind of fingerprint. It is necessary to clarify how the trends of the individual lines are to be understood. If the function in the figures is completely flat and horizontal, it means that the criterion is wholly insensitive to the phase shift effect. If such figures were to be prepared for the Papadopoulos method or for the MMP method, this would be the typical course for all load conditions (and this is the reason why such graphs were not prepared). If the function goes downwards (which is typical for most criteria and for most load cases), the response of the method to increasing phase shift is such that higher stress amplitudes could be applied to get to the same equivalent fatigue strength as with the in-phase load case. This means a non-zero phase shift increases the admissible stress, or the available fatigue life, in such cases. The relatively rare cases where the function exceeds a ratio of 1.00 relate to cases where the application of a non-zero phase shift worsens the situation and leads to lower fatigue strengths or shorter fatigue lives. 

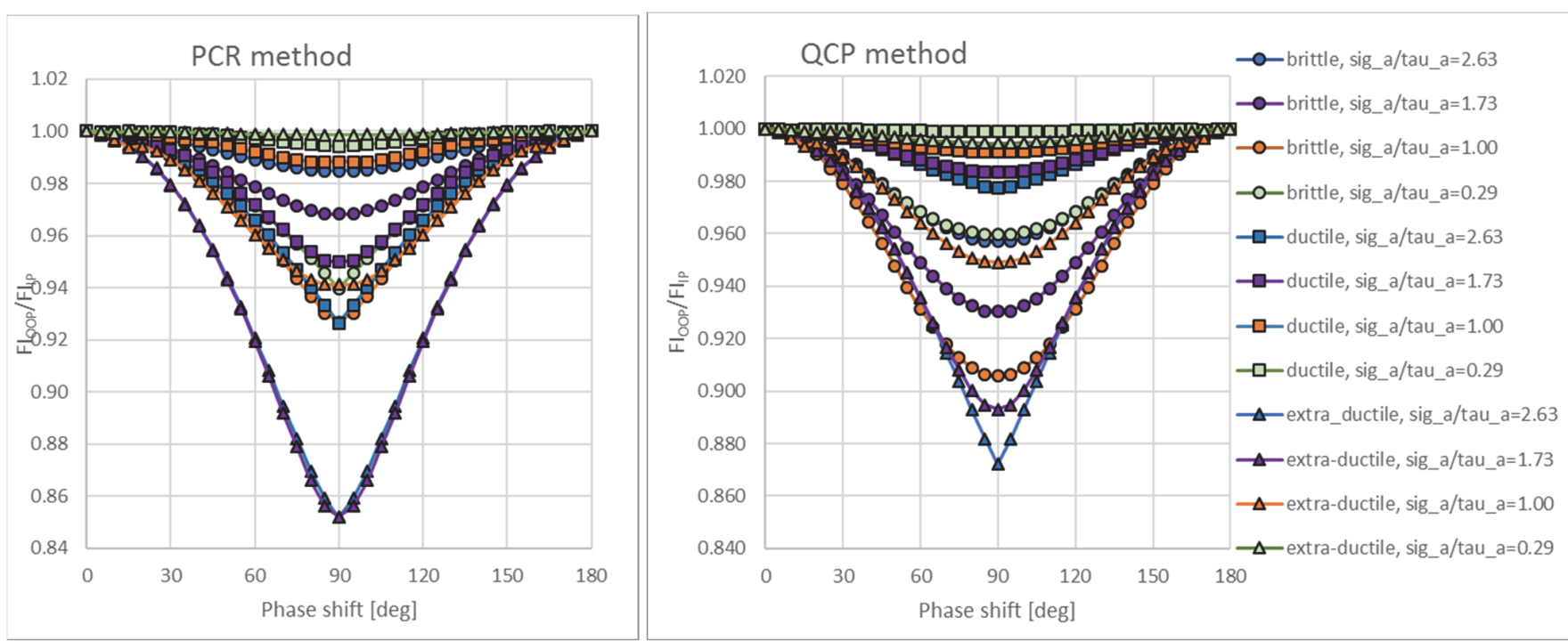

Figure 6: Results of the sensitivity analysis on critical plane criteria of the maximum damage type.
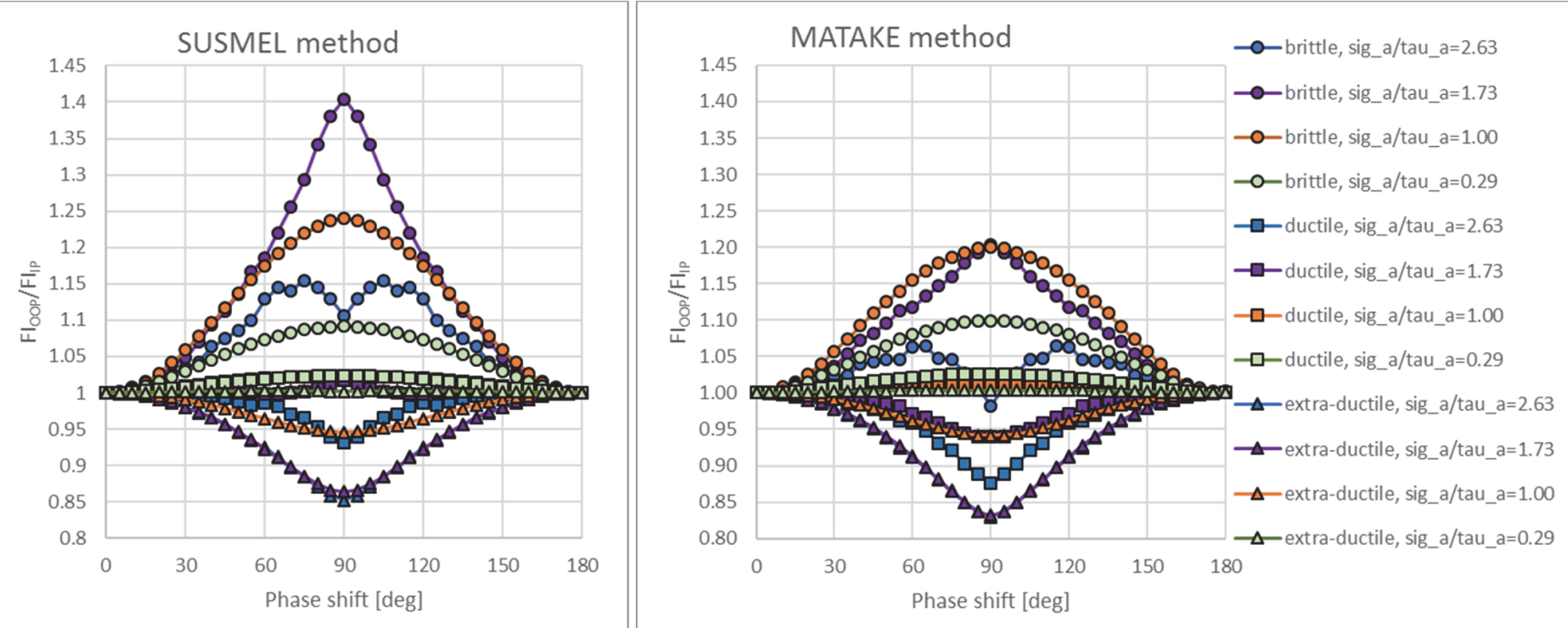

Figure 7: Results of the sensitivity analysis on critical plane criteria of the maximum shear stress range (MSSR) type.

The maximum damage critical plane criteria presented in Fig. 6 show that a non-zero phase shift increases the fatigue life. Both methods are quite insensitive to the phase shift effect if the torsion load channel is prevalent. The only exception in both cases is for a brittle material, where a decrease of approx. 5\% can be observed. The most radical increase in fatigue strength is for extra-ductile materials, if axial stress is dominant.

The criteria that look first for the critical plane related to the maximum shear stress range (see Fig. 7) provide a radically different response, above all for brittle materials. The response of the Susmel criterion to a stress ratio of 1.73 is not encountered by any other criterion in the tested set - the phase shift effect predicted by the Susmel method for this setup is so high that it should be obviously measurable. The response to the phase shift effect by a ductile material is not so pronounced, and a loading with dominant axial stress would be the most effective for confirming the effect. Both criteria show more visible phase shift dependency for an extra-ductile material than for a ductile material, as do other prediction methods.

The Dang Van method in the original version (DVO) shows higher phase shift dependency (to increase the admissible stresses for a non-zero phase shift) than most other methods - see Fig. 8. The most sensitive response of the method is to a stress ratio of 1.73 , but the values for brittle materials and for a stress ratio of 1.00 are also quite extreme. The modified Dang Van method presents reduced dependency, there is almost no phase shift effect for the dominant torsion channel, and the results also predict a relatively mild effect for a stress ratio of 1.00. The use of ductile or extra-ductile materials with 
dominant axial loading leads to the greatest differences. These cases could serve for proving whether the phase shift effect of these criteria is adequate.
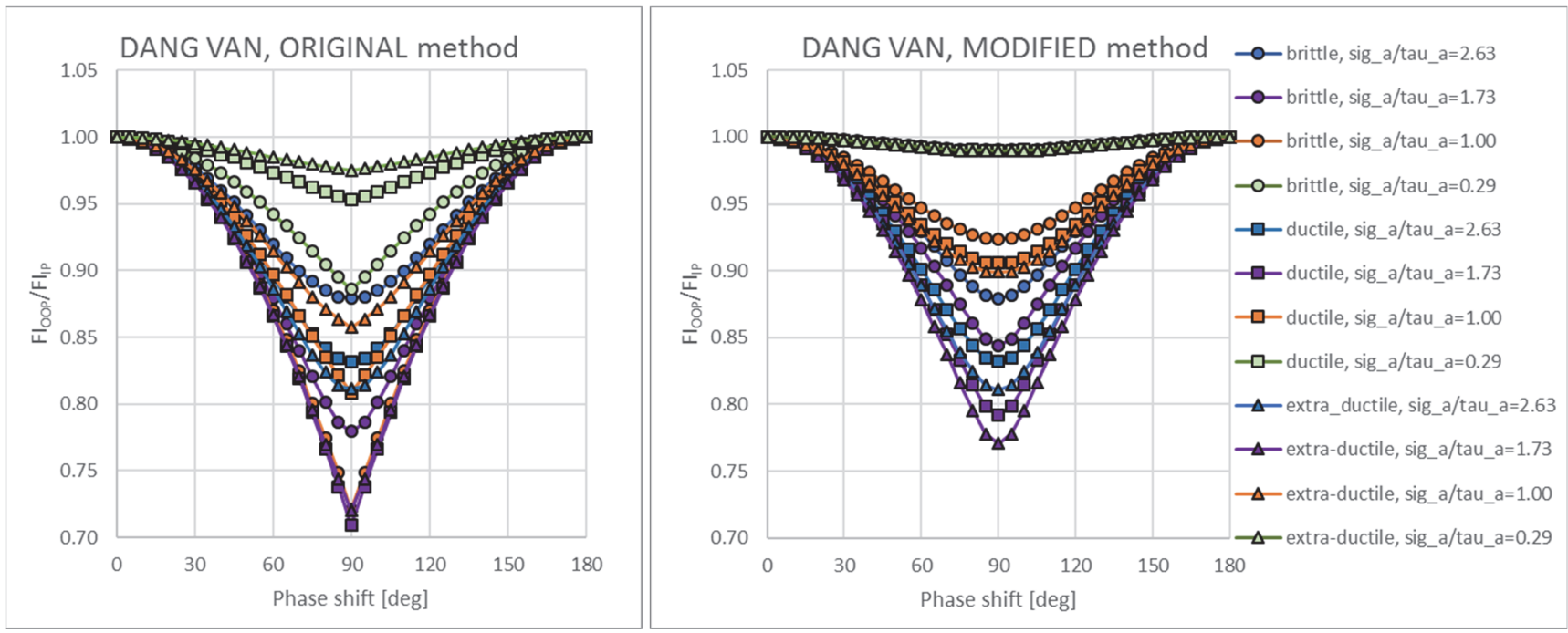

Figure 8: Results of the sensitivity analysis on two versions of the Dang Van method.
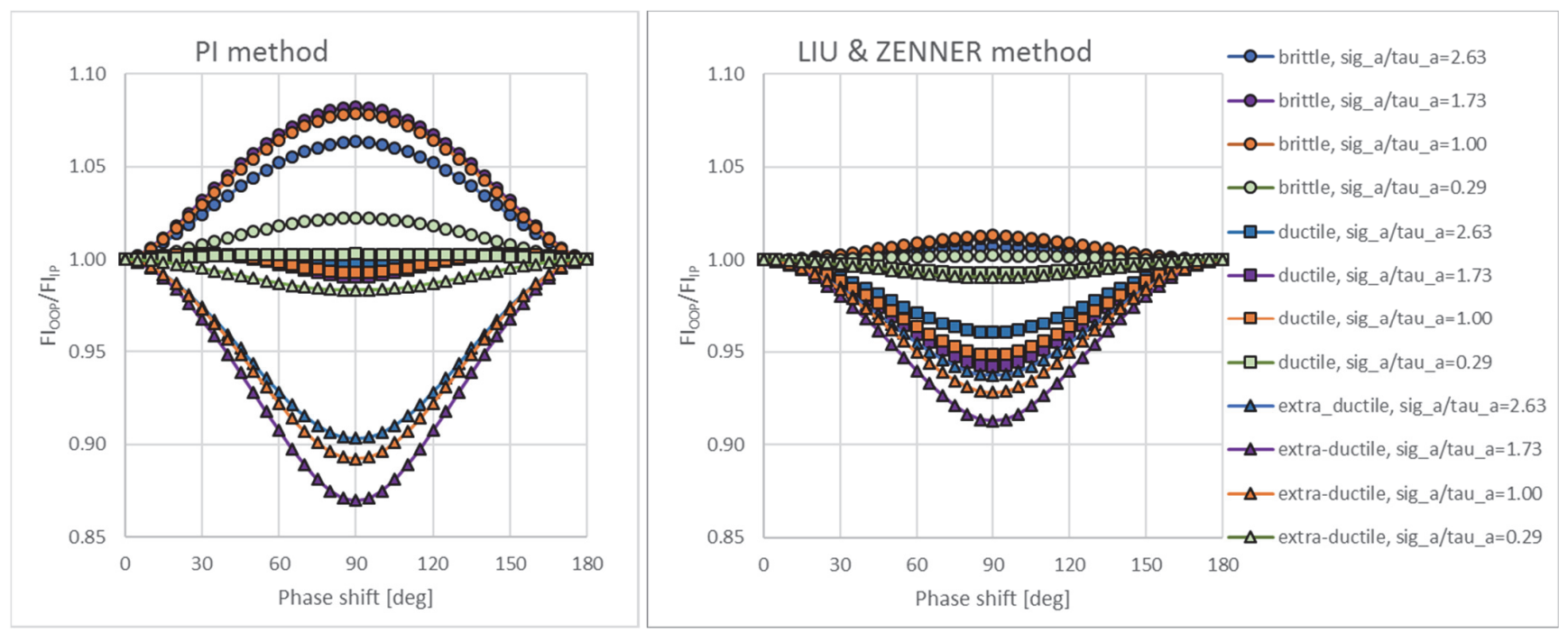

Figure 9: Results of the sensitivity analysis on two integral criteria.

The integral methods shown in Fig. 9 show behavior similar with critical plane criteria of the MSSR type, i.e. with the nonzero phase shift worsening the fatigue response for brittle materials. This effect can be observed above all for the PI method, while it is less prominent for the Liu \& Zenner method. The phase shift effect is also pronounced for extra-ductile materials, where it improves the fatigue response. The phase shift effect approaches minimum values for load cases with dominant torsion. The phase shift effect of the PI method for a ductile material approaches zero - it would obviously be hard to detect in experiments. There are some load combinations by the Liu \& Zenner method, where the phase shift effect for ductile materials exceeds $5 \%$ difference.

The behavior of the Crossland method in Fig. 10 quite well resembles Fig. 8 for the original Dang Van solution. The phase shift effect of all materials for a stress ratio of 1.73 would be easily detectable in any experiment. The Liu \& Mahadevan method, also shown in Fig. 10, draws attention to another interesting consideration - the functions show a slightly irregular character. This is probably caused by the two-level search for the final critical plane. Unlike all other methods, the method by Papadopoulos and the MMP method would show only a horizontal line in graphs similar to Figs. 6-10 at the position $F I_{O O P} / F I_{I P}=1.0$. These two methods could not be distinguished from each other by the trend of the phase-shift effect alone. 
In addition to the graphs in Figs. 6-10, Tab. 5 has been prepared. It shows cases for which the individual fatigue strength estimation methods result in a more accentuated difference between in-phase loading and out-of-phase loading. The higher the phase shift effect in those highlighted cases, the more easily it could be proven in an experimental campaign. Extraductile materials show the greatest dependency on the phase shift, so materials from this group would be perfect candidates for proving the prediction quality of each method. This effect is less visible for brittle materials, while ductile materials (to which all the remaining data sets in Tabs. 1-2 belong) produce the smallest differences.
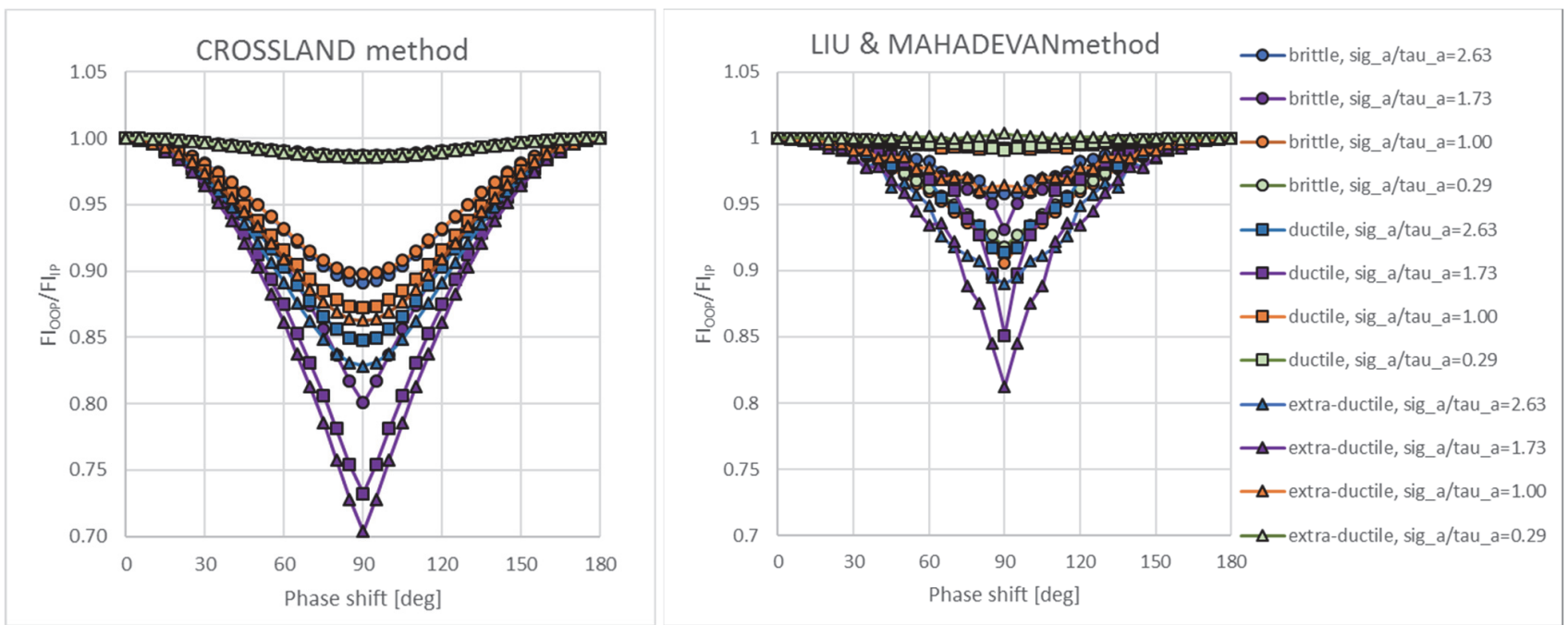

Figure 10: Results of the sensitivity analysis on the Crossland method (left) and the Liu \& Mahadevan method (right).

\begin{tabular}{lcccccccccccc}
\hline Material class: & \multicolumn{3}{c}{ Brittle } & \multicolumn{4}{c}{ Ductile } & \multicolumn{3}{c}{ Extra-Ductile } \\
$\sigma_{a} / \tau_{a}:$ & 2.63 & 1.73 & 1.00 & 0.29 & 2.63 & 1.73 & 1.00 & 0.29 & 2.63 & 1.73 & 1.00 & 0.29 \\
PCR & & & $>5$ & $>5$ & $>5$ & $>5$ & & $>10$ & $>10$ & $>5$ \\
QCP & $>5$ & $>5$ & & & & & $>10$ & $>10$ & $>5$ \\
Susmel & $>10$ & $>10$ & $>10$ & $>5$ & $>5$ & & & $>10$ & $>10$ & $>5$ \\
Matake & $>5^{*}$ & $>10$ & $>10$ & & $>10$ & $>5$ & & & $>10$ & $>5$ \\
DV, orig. & $>10$ & $>10$ & $>10$ & $>10$ & $>10$ & $>10$ & $>10$ & $>10$ & $>10$ & $>10$ \\
DV, mod. & $>10$ & $>10$ & $>5$ & & $>10$ & $>10$ & $>5$ & $>10$ & $>10$ & $>10$ \\
PI & $>5$ & $>5$ & $>5$ & & & & & $>5$ & $>10$ & $>10$ \\
Liu \& Zenner & & & & & & $>5$ & $>5$ & $>5$ & $>5$ & $>5$ \\
Crossland & $>10$ & $>10$ & $>10$ & & $>10$ & $>10$ & $>10$ & $>10$ & $>10$ & $>10$ \\
Liu \& Mahadevan & & $>5$ & $>5$ & $>5$ & $>5$ & $>10$ & & $>10$ & $>10$ & \\
\hline
\end{tabular}

Table 5: A summary providing a quick overview of the size of the absolute value of the fatigue index error change in \%, if switching from in-phase to out-of phase loading. The sign " $>$ " means the criterion results in the fatigue index change higher than the stated value.. Higher values of $\Delta F I$ should be easier to detect in an experimental campaign.

\section{DisCussion}

7 he data items presented in Tab. 3 are so sparse, and there are so many other potential effects that could affect the results, that it does not make sense to base any final verdict on them. Note the interesting consideration that all remaining experiments covered in Tabs. 1-3 could be classified under ductile materials in Tab. 5, while the range of their fatigue strength ratios is extremely small: $\kappa=1.47-1.48$. With the exception of the FF experiments, which are expected to be affected by the use of inadequate fatigue strength in pure torsion loading, the equivalent stress ratios $\sigma_{M M P, 90} / \sigma_{M M P, 0}$ span from 0.94 to 0.97 , and the out-of-phase loading would lead to lower fatigue strengths. The phase shift effect is very moderate in those experiments. If they were the only values to be evaluated, while the applied stress ratio spans from 1.00 
to 3.00 for these test cases, the Dang Van method, the Crossland method, the Matake method and the Liu\&Mahadevan method could be crossed out as unsuccessful candidates.

If the results in Tab. 3 are evaluated separately in groups of in-phase experiments and out-of-phase experiments, it is striking that the in-phase experiments are usually well modelled by all evaluated criteria (maybe with the exception of the Dang Van method and the Matake method). The in-phase experiments are the least complex and the least problematic for fatigue strength prediction. It is therefore reasonable to include them in an experimental campaign only when they are accompanied either by out-of-phase cases or generally by non-proportional cases, or when there are some other effects not covered here (e.g. the mean stress effect). Experimental data sets dealing only with in-phase loads provide only a limited amount of new information.

The decision to remove the prediction values for the FF experiments from the analyses concerns only the fatigue strength estimation results. These rely on a correct value of the fatigue strength in fully reversed torsion, which is not available for this test set. This does not mean, however, that the experiments themselves, shown in Fig. 4, are wrong. The setup of the FF experiments differs somewhat from the usual setup for similar experiments. Instead of keeping the same stress ratio over all lifetimes, only the torsion channel is kept variable, while the axial load channel is kept constant. The graph in Fig. 4 therefore shows the real response to the phase shift effect of the FF002-FF004 pair, where the shear stress amplitude value in the out-of-phase case is much higher than in the in-phase variant. Anyhow, quantifying the response by the ratio of the $\sigma_{M M P}$ equivalent stresses is misleading - such step assumes that this stress norm (the MMP method) is perfect, and should therefore be avoided. At least the experimental trends can be evaluated. The fatigue life improves in the out-of-phase load cases in comparison with the in-phase cases for the FF experiments, while the opposite trend is valid for the SiB and FAD experiments.

The fatigue strength ratios for all three data sets are very similar, and the stress ratio effect does not seem to be dominant. Is there any other potential effect that may be causing these differences? Tab. 2 presents another comparison, which is $d / D$ ratio of the minor diameter to the major diameter of specimens. While both specimens (FAD and $\mathrm{SiB}$ ) that show worsening fatigue strength with an increasing phase shift can be categorized as thin-walled (each wall presents approx.. $5 \%$ of the diameter), this is far from true for the FF experiments, where each wall presents more than $10 \%$. The doubt as regards mixing the initiation phase and the crack growth phases together can be recalled again for the FF specimens. Because of the rotation of the principal directions during the crack growth phase in the out-of-phase loading scenario, the crack growth can be slowed down, which would increase the lifetime for an out-of-phase load, in conformity with the observed trend. In [48], Papuga et al. highlighted another interesting consideration. A push test of a thin-walled hollow specimen results in the stress distribution across the wall, where the inner surface is more loaded than the outer surface (see Fig. 11). Because the torsion case invokes higher stresses on the outer surface, the out-of-phase loading can switch the location of the hotspot during out-of-phase loading from one surface to another during each load period. The numerical tests in [48] showed that the increase in the stress level at the inner surface in push-pull is dependent above all on Poisson's ratio, and on the radius of the fillet between the gripping diameter and the major diameter in the critical cross-section. The effect of wall thickness was not checked. The comparison in Fig. 11 shows that the thicker wall of the FF specimens results in the smallest stress gradient and the smallest stress difference between the two surfaces. The change in the axial stress between the two surfaces is far lower than the stress gradient induced by the torsion loading. However, it does exist, and it complicates the analysis of the out-of-phase load cases - both surfaces should be checked above all when the axial stress is substantially higher than the shear stress, which results in a milder shear stress gradient. This characteristic is not covered in Figs. 6-10, which refer to nominal stresses only obtained on the outer surface of the specimens.

\section{Proposed setup of the decisive test}

An extensive search has been made for experimental data that is qualitatively good enough to prove that some of the multiaxial fatigue strength criteria discussed here work well. However, it has been found that almost no such data are in fact available. Tab. 5 presents some candidates that are right for certain types of materials and stress ratios, and provides some data that give evidence for confirming or dismissing the calculation methods that have been presented. A summary of the attributes of the adequate test campaign in support of this argumentation follows:

1. Two S-N fatigue curves in pure fully-reversed push-pull and in fully-reversed pure torsion will be prepared to present the material data. A pair of further S-N curves will be prepared, which combine axial and torsion load channels at similar amplitudes and with the same stress ratio between the two load channels. One of these S-N curve should be run in the in-phase configuration and the other in the out-of-phase configuration, preferably with $90^{\circ}$ phase shift.

2. Each of the fatigue curves is defined on the basis of adequate number of experiments to enable a description of the high-cycle fatigue behaviour, and the longest possible lifetime close to the transition to the fatigue limit region. 
The number of specimens per a curve should exceed 12, and the use of the pearl string strategy is preferred over the $\mathrm{x}$-level strategy.

3. An S-N model that enable the fatigue limit region to be involved in the regression formula (e.g. the Kohout-Verchet formula) is preferred over the widely-used Basquin two-parametric formula, in order to obtain the trends.

4. All fatigue tests should be preceded by a test on the concentricity of the testing machine grips with the axis of the specimen.

5. Hollow specimens with thin walls $(d / D>0.9)$ are preferred in order to reduce the crack growth phase effect as the simplest solution to cope with separating the crack initiation phase and the crack growth phase (by reducing the latter to negligibility). If bar specimens are used, the time to crack initiation should be monitored as the main criterion for ending the test.

6. All $4 \mathrm{~S}-\mathrm{N}$ curves should be retrieved from experiments performed on an identical specimen geometry with an identical surface finish. All specimens should be manufactured from material from the same batch.

7. At least tensile static tests should be performed to ensure the level of potential anisotropy of the material, which could affect the results of fatigue tests in different load cases. At the first level, the acceptably isotropic cases can serve to define the optimum computational strategy. The cases where significant anisotropy is found should be evaluated in the second round, while implementing the adequate computational strategy to the already selected multiaxial fatigue strength method.

It is feasible to perform such tests. The response of the individual criteria to such conditions can be evaluated quickly, and could serve for reaching a final verdict on strategy - among so many discussed here - that is the best for out-of-phase loading. The mean stress effect can be tuned afterwards.
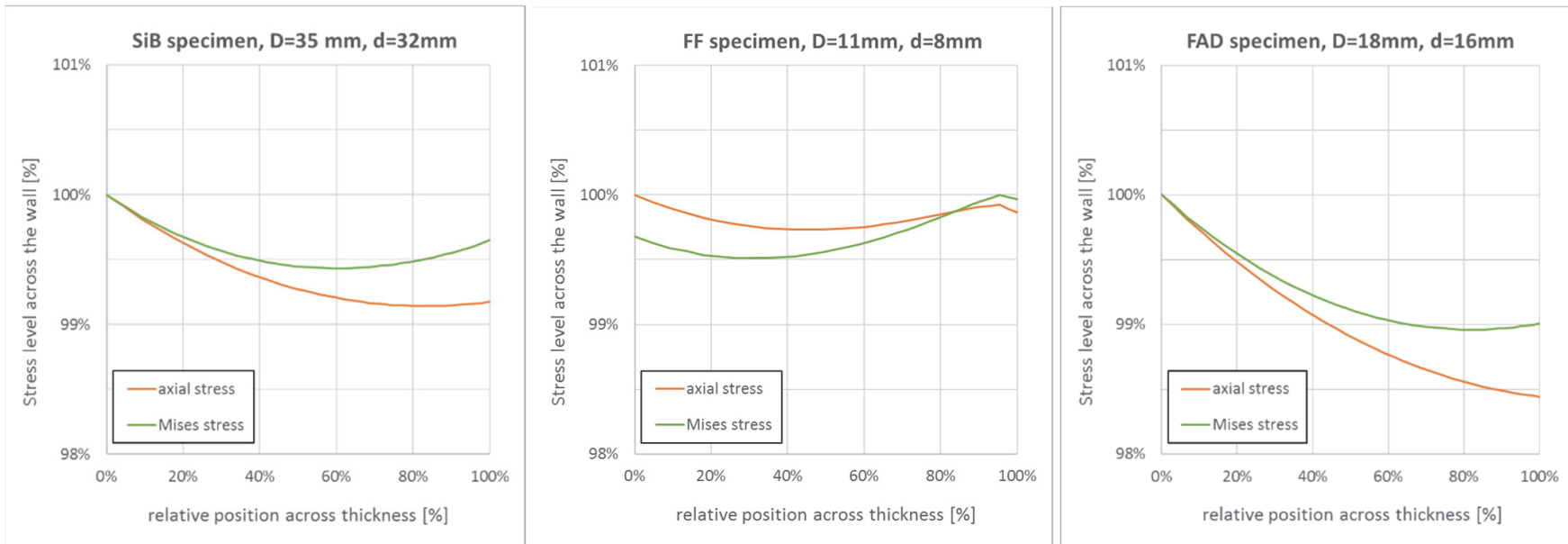

Figure 11: Changes in the axial and Mises stress levels across the wall thickness of hollow specimens, where $0 \%$ corresponds to the inner wall, and $100 \%$ corresponds to the outer wall.

\section{CONCLUSION}

7 his paper has highlighted the phase shift effect as the primary effect that should be well mastered by any multiaxial fatigue strength criterion. It discusses the ways in which the phase shift effect is dealt with, and how it is evaluated. It proposes comparing the admissible stresses on individual channels in in-phase and $90^{\circ}$ out-of-phase combinations of push-pull and torsion loading, while the same stress ratio between both load channels is kept, and no mean stress is allowed. Whether a non-zero phase shift between the two load channels increases or decreases the admissible stresses for a given lifetime, in comparison with the in-phase variant, provides clear evidence of the existence or non-existence of a phase shift effect.

The authors have selected and presented various fatigue strength estimation criteria, and they have explained their basic functionality, and differences between various computational strategies. A sensitivity analysis was then run for each of the criteria to show how the non-zero phase shift affects the output admissible stress for various types of materials, and for various stress ratios on the two load channels for different fatigue strength estimation criteria. The graphs in Figs. 6-10 and the summary in Tab. 5 show that all analysed computational methods differ substantially from each other. It is obvious 
from the graphs that the trends for most criteria are quite well visible and could be proven by adequately controlled experimental campaign.

The authors have attempted to establish a test matrix to prove their finding. Although they have devoted many years to assembling and evaluating experimental data for similar benchmark tests, the conditions stated above have been met only by a small number of tests, two of which were then expelled for not being good enough. Because these tests have been run without understanding in advance how the phase shift effect could affect the results, the remaining data items fall into the region where the phase shift effect can be very mild according to many evaluated criteria. This places even higher importance on good substantiation of the experimental data that are used (qualitatively well described fatigue curves, i.e. an adequate number of experimental data points on them). The same finding again highlights the reasons for strict requirements on experimental data quality, which were applied when the data sets were being gathered.

For these reasons, no conclusion could be reached about a method that covers the phase shift effect optimally. Instead, an optimal setup for such experimental proof was proposed, so that the problem can be evaluated and the verdict can be finalized.

\section{ACKNOWLEDGEMENT}

7 he authors thankfully acknowledge funding for this research from the European Union's Horizon 2020 research and innovation programme, under Grant Agreement No. 653941, and from the Grant Agency of the Czech Technical University in Prague (Grant No. SGS17/175/OHK2/3T/12).

\section{REFERENCES}

[1] Papuga, J. (2011). A survey on evaluating the fatigue limit under multiaxial loading. Int J Fatigue, 33, pp. 153-165. DOI: $10.1016 /$ j.ijfatigue.2010.08.001

[2] Rennert, R., Kullig, E., Vormwald, M., Esderts, A. and Siegele, D. (2012). FKM-Richtlinie - Rechnerischer Festigkeitsnachweis für Maschinenbauteile. [6. revised version], Frankfurt/Main, VDMA Verlag GmbH.

[3] Sonsino, C. M. (2001). Influence of load and deformation-controlled multiaxial tests on fatigue life to crack initiation. Int J Fatigue, 23(2), pp. 159-167. DOI: 10.1016/S0142-1123(00)00079-7.

[4] Sonsino, C. M. (2011). Influence of material's ductility and local deformation mode on multiaxial fatigue response. Int J Fatigue, 33(8), pp. 930-947. DOI: 10.1016/j.ijfatigue.2011.01.010.

[5] Löwisch, G and Bomas, H. (1997). Ermüdung des Stahles 42CrMo 4 unter mehrachsiger phasenverschobener Beanspruchung. [Abschlussbericht zum AiF-Forschungsvorhaben Nr. 10058]. Bremen, Amtliche Materialprüfungsanstalt (MPA).

[6] Hug, J. (1994). Einfluss mehrachsiger Beanspruchung auf die Lebensdauer im Zeitfestigkeitsgebiet. [PhD thesis]. Technische Universität Clausthal, Clausthal-Zellerfeld.

[7] Simbürger A. (1975). Festigkeitsverhalten zäher Werkstoffe bei einer mehrachsigen phasenverschobenen Schwingbeanspruchung mit körperfesten und veränderlichen Hauptspannungsrichtungen. [PhD thesis]. Darmstadt: TH Darmstadt.

[8] Papadopoulos, I. V., Davoli, P., Gorla, C., Filippini, M. and Bernasconi, A. (1997). A comparative study of multiaxial high-cycle fatigue criteria for metals. Int J Fatigue, 19, pp. 219-235. DOI: 10.1016/S0142-1123(96)00064-3.

[9] Banvillet, A., Palin-Luc, T. and Lasserre, S. (2003). A volumetric energy based high cycle multiaxial fatigue criterion. Int J Fatigue, 25, pp. 755-769. DOI: 10.1016/S0142-1123(03)00048-3.

[10] Braccesi, C., Cianetti, F., Lori, G. and Pioli, D. (2008). An equivalent uniaxial stress process for fatigue life estimation of mechanical components under multiaxial stress conditions. Int J Fatigue, 30, pp. 1479-1497.

DOI: 10.1016/j.ijfatigue.2007.09.011

[11] Kluger, K., Lagoda, T. (2014). New energy model for fatigue life determination under multiaxial loading with different mean values. Int J Fatigue, 66, pp. 229-245. DOI: 10.1016/j.ijfatigue.2014.04.008.

[12] Bruun, Ø.A. and Härkegård, G. (2015). A comparative study of design code criteria for prediction of the fatigue limit under in-phase and out-of-phase tension-torsion cycles. Int J Fatigue, 73, pp. 1-16. DOI: 10.1016/j.ijfatigue.2014.10.015.

[13] Papuga, J. and Halama, R. (2018). Mean stress effect in multiaxial fatigue limit criteria. R. Arch Appl Mech.

DOI: $10.1007 / \mathrm{s} 00419-018-1421-7$. 
[14] Nishihara, T. and Kawamoto, M. (1945). The strength of metals under combined alternating bending and torsion with phase difference. Memoirs of the College of Science and Engineering, Kyoto Imperial University, 11, pp. 85-112.

[15] Papuga, J. (2013). Quest for Fatigue Limit Prediction Under Multiaxial Loading. Procedia Engineering, 66, pp. 587-597. DOI: $10.1016 /$ j.proeng.2013.12.110.

[16] Ioannidis, J. P. (2005). Why most published research findings are false. PLoS Med., 2(8), e124. DOI: $10.1371 /$ journal.pmed.0020124.

[17] Lempp, W. (1977). Festigkeitsverhalten von Stählen bei mehrachsiger Dauerschwingbeanspruchung durch Normalspannungen mit überlagerten phasengleichen und phasenverschobenen Schubspannungen, [PhD thesis], Stuttgart Technische Universität Stuttgart.

[18] Heidenreich, R., Schubspannungsintensitätshypothese - Dauerschwingfestigkeit bei mehrachsiger Beanspruchung [Forschungshefte FKM, Heft 105]. Frankfurt am Main - Niederrad, FKM.

[19] Froustey, C. and Lasserre, S. (1988). Fatigue des aciers sous sollicitations combinees. Application a l'acier 30 NCD16. [Technical report Rapport DRET-LAMEF-ENSAM. contrat 87/115], Talence, ENSAM.

[20] Pejkowski, L. (2017). On the material's sensitivity to non-proportionality of fatigue loading. Archives of Civil and Mechanical Engineering 17, pp. 711-727.

[21] Rotvel, F. (1970). Biaxial fatigue tests with zero mean stresses using tubular specimens. Int Jnl. of Mech. Sci., 12, pp. 597-613.

[22] Papuga, J., Vízková, I., Nesládek, M. and Trubelová, Š. (2018). Validation data set for testing the criteria for multiaxial fatigue strength estimation. Fatigue \& Fracture of Engineering Materials \& Structures, 41(11), pp. $2259-2271$.

DOI: $10.1111 /$ ffe.12822, 2018, pp. 1-13.

[23] Zenner, H., Simbürger, A. and Liu, J. (2000). On the fatigue limit of ductile metals under complex multiaxial loading. International Journal of Fatigue, 22(2), pp. 137-145.

[24] Liu, Y., Mahadevan, S. (2005). Multiaxial high-cycle fatigue criterion and life prediction for metals. International Journal of Fatigue, 27, pp. 790-800.

[25] Papuga, J. and Fojtík, F. (2017). Multiaxial fatigue strength of common structural steel and the response of some estimation methods. International Journal of Fatigue, 104, pp. 27-42. DOI: 10.1016/j.ijfatigue.2017.07.001.

[26] Lüpfert, H.-P. and Spies, H.-J. (2004). Fatigue strength of heat-treatable steel under static multiaxial compression stresses. Advanced Engineering Materials, 6(7), pp. 544-550. DOI: 10.1002/adem.200400413.

[27] Cláudio, R. A., Reis, L. and Freitas, M. (2014). Biaxial high-cycle fatigue life assessment of ductile aluminium cruciform specimens. Theoretical and Applied Fracture Mechanics, 73, pp. 82-90. DOI: 10.1016/j.tafmec.2014.08.007.

[28] Gough, H.J. and Pollard, H.V. (1935). The strength of metals under combined alternating stresses, in: Proc. of Institute of Mechanical Engineering, Proc. of the Institution of Automobile Engineers, 131, pp. 1-103.

[29] Gough, H.J. and Pollard, H.V. (1937). Properties of some materials for cast crankshafts, with special reference to combined stresses, Proc. of the Institution of Automobile Engineers, pp. 821-893.

[30] Gough, H.J. (1950). Engineering steels under combined cyclic and static stresses, Journal of Applied Mechanics, pp. 113-125.

[31] Findley, W. N. (1953). Combined-stress fatigue strength of 76S-T61 aluminum alloy with superimposed mean stresses and corrections for yielding. [Technical report NACA TN-2924]. Washington, NACA.

[32] Major, Š., Papuga, J., Horníková, J., Pokluda, J. (2008). Comparison of fatigue criteria for combined bending-torsion loading of nitrided and virgin specimens. Strength of Materials 40(1), pp. 64-66.

[33] Socie, D. F. (1993). Critical plane approaches for multiaxial fatigue damage assessment. In: Advances in Multiaxial Fatigue, ASTM STP 1191. D. L. Dowell and R. Ellis, Eds., Philadelphia, ASTM, pp. 7-36.

[34] Klubberg, F., Broeckmann, C. and Beiss, P. (2012). Festigkeitskennwerte und mehrachsige Schwingfestigkeit von lamellaren Gusseisen. Mater. Test., 54(9), pp. 569-577.

[35] Tanaka, K. (2014). Crack initiation and propagation in torsional fatigue of circumferentially notched steel bars. International Journal of Fatigue, 58, pp. 114-125. DOI: 10.1016/j.ijfatigue.2013.01.002.

[36] Papuga, J., Nesládek, M. and Jurenka, J. (2018). Parameters affecting the response to non-proportional fatigue loading. In: Proc. of $18^{\text {th }}$ International Conference on New Trends in Fatigue and Fracture. L. Reis, M. Freitas and V. Anes, Eds. Lisbon, IST University of Lisbon, pp. 23-26.

[37] Kohout J. and Věchet S. (2001). A new function for fatigue curves characterization and its multiple merits. Int J Fatigue, 23(2), pp. 175-183. DOI: 10.1016/S0142-1123(00)00082-7

[38] Papuga, J., Fojtík, F., Vargas, M., Hodr, A., Karolczuk, A., Fusek, M. and Halama, R.: Summary of experiments on 2124T851 realized within FADOFF project. [Technical report FAD/14/001]. Prague, CTU in Prague. 
[39] Susmel, L. (2011). Comments on "A survey on evaluating the fatigue limit under multiaxial loading" by Jan Papuga [Int J Fatigue 33 (2011) 153-165]. Int J Fatigue. 33(10), pp.1392-1395. DOI: 10.1016/j.ijfatigue.2011.04.005.

[40] Matake, T. (1977). An explanation on fatigue limit under combined stress. Bull JSME, 20, pp. 257-63.

[41] McDiarmid, D.L. (1991). A general criterion for high cycle multiaxial fatigue failure. Fatigue Fract Eng Mater Struct, 14, pp. 429-53.

[42] Dang Van, K. (1973) Sur la résistance à la fatigue des métaux. [PhD thesis],Sci Techniq l'Armement 47, pp. 647.

[43] Papuga, J. and Růžička, M. (2008). Two new multiaxial criteria for high cycle fatigue computation, Int. Jnl. of Fatigue, 30, pp. 58-66. DOI: 10.1016/j.ijfatigue.2007.02.015.

[44] Tomčala, J., Papuga, J., Horák, D., Hapla, V., Pecha, M. and Čermák, M. (2018). Steps to increase practical applicability of PragTic software. Advances in Engineering Software. DOI: 10.1016/j.advengsoft.2018.06.009.

[45] Kenmeugne, J. L., Vidal-Salle, E., Robert, J. L. and BAHUAUD, R. J. (1996). On a new multiaxial fatigue criterion based on a selective integration approach. In: Fatigue '96, Proc. of the Sixth Int. Fatigue Congress, Vol. II. G. Lütjering, Ed., Berlin, Pergamon, pp. 1013-1018.

[46] Papuga J. (2011). Answer to comments on "A survey on evaluating the fatigue limit under multiaxial loading" [Int J Fatigue 33 (2011) 153-165]. Int J Fatigue. 33(10), pp. 1396-1402. DOI: 10.1016/j.ijfatigue.2011.04.006).

[47] Papuga, J. (2018). Database of Fatigue Limits - Job File for PragTic. Available at: http://www.pragtic.com/FL_job.php.

[48] Papuga, J., Vargas, M. and Růžička, M. (2015). Wiles of Using Hollow Specimens for Fatigue Tests. Applied Mechanics and Materials, 732, pp. 71-76. DOI: 10.4028/www.scientific.net/AMM.732.71. 